\title{
Comparison of three land-surface schemes with the Fourier amplitude sensitivity test (FAST)
}

\author{
By ERNESTO RODRÍGUEZ-CAMINO ${ }^{1 *}$ AND RONI AVISSAR ${ }^{2}$, ${ }^{1}$ Instituto Nacional de \\ Meteorología, Madrid, Spain; ${ }^{2}$ Department of Environmental Sciences, Rutgers University, New Brunswick, \\ New Jersey, USA
}

(Manuscript received 20 May 1997; in final form 8 December 1997)

\begin{abstract}
This paper explores which are the land-surface parameters playing a key role in three surface schemes, namely the land-atmosphere interactive dynamics (LAID), the interaction soil-biosphere-atmosphere (ISBA) and the biosphere-atmosphere transfer scheme (BATS). The Fourier amplitude sensitivity test (FAST) was used for that purpose. This test estimates the relative contribution of model input parameters to the variance of surface heat fluxes. This analysis demonstrates that, for the three considered schemes, four parameters can explain most of the variance of surface heat fluxes under a broad range of environmental conditions. Soil wetness plays a predominant rôle for the heat fluxes. Roughness length is the most important parameter for the momentum flux. Leaf area index, in vegetated land, and texture, mainly in bare land, also have a significant impact on the fluxes. Roughness length is usually more important for sensible heat flux than for latent heat flux, and is mostly important under stable atmospheric conditions. Soil wetness and vegetation parameters are the dominant parameters under buoyant conditions.
\end{abstract}

\section{Introduction}

Several investigations have already addressed the importance of the different land-surface parameters in atmospheric modelling (Mintz, 1984; Walker and Rowntree, 1977; Rowntree and Bolton, 1978; Miyakoda and Strickler, 1981; Shukla and Mintz, 1982; Charney et al., 1977; Chervin, 1978; Carson and Sangster, 1981; Sud et al., 1988; Dickinson and Henderson-Sellers, 1988; Sud et al., 1990; Henderson-Sellers, 1993, 1996a, 1996b, 1996c). Representation of landscape subgrid-scale heterogeneity has been simulated either by dividing each grid square of the modeled domain into multiple homogeneous regions (Avissar and Pielke, 1989; Koster and Suarez, 1992) or by statistical-dynamical approaches using

\footnotetext{
* Corresponding author
}

probability density functions (PDF) to describe the variability of land-surface characteristics (Famiglietti and Wood, 1991; Avissar, 1991, 1992). Collins and Avissar (1994) have first used the Fourier Amplitude Sensitivity Test (FAST) to estimate the relative importance of land-surface parameters. The impact of microscale variability of the most important land-surface characteristics on atmospheric turbulent heat fluxes near the ground surface has been investigated by $\mathrm{Li}$ and Avissar (1994). The Project for Intercomparison of Land-surface Parameterization Schemes (PILPS) (Henderson-Sellers et al., 1993, 1995) emphasizes the needs for sensitivity intercomparisons studies to identify which simplifications or omissions are important to improve our understanding of the parameterizations of the interactions between the atmosphere and the continental surface in climate and weather forecast models. 
The radiative solar and atmospheric fluxes absorbed by land-surface are mainly redistributed as latent and sensible heat. Both heat fluxes are the main mechanisms to turn back energy into the atmosphere from land surface. The relative importance of latent and sensible heat fluxes depend strongly on surface features. In bare, dry soils, the absorbed radiative energy is mostly used to heat the surface, turning back the energy to the atmosphere usually as a vigorous, turbulent sensible flux. On the other hand, densely vegetated surfaces with enough water available for evapotranspiration invest most of the radiative energy in extracting subsurface water through the root system. This process of transpiration is mainly controlled by leaves, opening and closing their stomata according to the environmental conditions and to the available soil wetness. Transpiration turns energy back to the atmosphere in form of latent heat flux (Garratt, 1992, among many others).

Between such extreme cases of dry, bare soils and densely vegetated wet terrains there are many intermediate land-surface conditions, whose behaviour is constrained by soil features, especially soil wetness and texture, and by the predominant vegetation type. The parameters describing soil and vegetation, together with atmospheric conditions, determine the magnitude of the surface heat fluxes and the Bowen ratio (the ratio of sensible to latent heat flux). Both ways of turning back energy to the atmosphere, either as sensible or as latent heat, are controlled by the ability of plants to moderate water consumption during transpiration under unfavorable environmental conditions. As mentioned above, stomata play a key role in controlling transpiration. Assuming that it is an independent parameter, Collins and Avissar (1994) showed that uncertainty in estimating this parameter results in the most important error in estimating surface fluxes under convective conditions.

However, stomatal conductance (or resistance) is generally not considered an independent parameter. It is well accepted (Jarvis, 1976) that this parameter is a function of various environmental conditions (solar radiation, air temperature, air relative humidity, soil wetness). When stomatal conductance (or resistance) is considered an independent parameter, it is allowed to vary freely between within some interval, independently of the environmental conditions. If, on the other hand, stomatal conductance (or resistance) is parameterized as a function of environmental conditions, the parameters controlling the stomata are those which are really relevant in computing surface heat fluxes. Because different land-surface schemes use different parameterizations to represent this processes, it is interesting to investigate the impacts of various parameters (assumed independent) in different schemes. This was the purpose of the study summarized in this paper.

This study will mainly demonstrate that soil wetness, which has a crucial impact on the stomatal mechanism, mostly affects the surface heat fluxes.

\section{Analysis with the Fourier amplitude sensitivity test (FAST)}

Typical sensitivity analysis of land-surface parameterizations to the variation of their parameters have assumed predetermination of the range of variation of all involved parameters. This range of variation must be related either to the degree of uncertainty associated with every measured parameter or to its use in the parameterization scheme. Henderson-Sellers (1993) proposed the following sources of uncertainty for the BATS parameters, which can be considered as general for every land-surface scheme: (i) original global archives; (ii) association of some particular parameter with a particular vegetation type; (iii) use of the parameter in the land-surface parameterization scheme; (iv) aggregation of the original data to the appropiate model resolution; and (v) the compilation procedure from different literature sources together with unclear prescriptions to some vegetation types when measurements exist only for one type.

Other important issues in sensitivity analysis arise when several parameters are modified simultaneously. Do all possible combinations of parameters exist in nature? What is the frequency of appearance of every combination? Obviously, if some possible combinations appear very rarely in nature, they should have a reduced weight in the analysis. In this paper, all combinations will be assumed possible if parameters are independent. Parameters are independent when their assigned value do not condition the value of the others. Of 
course, that excludes the parameters which can be expressed as a function of others. Usually, landsurface parameters are considered independent only as a first approximation. For instance, one can expect that high values of soil wetness are associated with dense vegetation and, consequently, with high values of leaf area index. On the other hand, vegetation cannot develop in dry soil. It is important to stress that the results of the analysis depend greatly on the selection of the parameters as well as on their range of variation. In current state-of-art land-surface schemes, at least 10 input parameters can be assumed to vary more or less independently. Several techniques are available for sensitivity analysis:

(1) The Monte Carlo method, which makes a random sampling of the entire input parameter space. It becomes computationally very expensive when the dimension of the input parameters space increases;

(2) The so-called factorial stratified sampling, which is the simplest technique available. A "high" and a "low" value can be chosen for each of the input parameters, representing the range of that parameter, and the model is run for all combinations of these high and low values. The number of computations grows exponentially with the dimension of the parameters space. If the parameters variability is distributed according to probability density functions (PDF), more than two values are needed to explore the impact of these parameters. For instance, if 10 values are needed to represent the PDF of each parameter, then the total number of computations to cover all possible combinations of these parameters is $10^{n}$. Such an approach becomes prohibitive as the dimension of input parameter space grows;

(3) Other stratified sampling techniques exist that are much more efficient, such as latin hypercube sampling (McKay et al., 1979). However, as the above mentioned ones, they do not provide model sensitivity to individual input parameters;

(4) The Fourier Amplitude Sensitivity Test (FAST) originally developed by Cukier et al. (1973), Cukier et al. (1975) and Cukier et al. (1978) is a general technique for sensitivity analysis of mathematical models. It has been applied by Uliasz (1988) to evaluate a Lagrangian long-range transport model, by Collins and Avissar (1994) to study the sensitivity of land-surface heat fluxes to land surface characteristics, and by Liu and
Avissar (1996) to study the sensitivity of shallow convective precipitation induced by land-surface heterogeneity to dynamical and cloud microphysical parameters. With this technique input parameters are varied simultaneously through their ranges of possible values according to some given PDF. All input parameters are assumed to be independent.

Each input parameter is assigned a different frequency, which determines the number of times that the whole range of the parameter is traversed. This frequency of oscillation, different for each parameter, is analyzed in the model output to separate the response of the model to every input frequency. Addition of those Fourier coefficients corresponding to a particular input parameter frequency and its harmonics determines the total contribution of that particular input parameter to the model output variances. The essence of this method consists of analyzing the spectrum of frequencies of model outputs generated when parameters are forced to oscillate with given linearly independent frequencies. Finally, by scaling the relative contribution of the input parameters to the total variance, partial variances are obtained which show the sensitivity of the model output parameters to the variation of the individual input parameters in their prescribed range of values. A description of the theory and implementation of the FAST method and approximations used in the computer code can be found in Collins and Avissar (1994).

Table 1 summarizes the number of model runs required by FAST as a function of the number of input parameters, which is substantially less than the number of integrations required by the Monte Carlo or the factorial stratified method (McRae et al., 1982).

The FAST technique is a very powerful technique for general sensitivity analysis in mathematical models, though it has also some limitations.

- Nonlinear algorithms connecting the input parameter and output parameter spaces can distort the real sensitivity caused by some input parameter. The FAST technique is mainly based on the analysis of the output parameters spectrum and on the relative weight of the harmonics associated with the input parameters. Nonlinear models -unlike the linear models-can alter the contributions corresponding to the set of harmonics associated with a given input parameter. Two harmonics 
Table 1. The minimum number of model runs required by FAST (after McRae, 1982)

\begin{tabular}{cc}
\hline No. parameters & No. model runs \\
\hline 2 & 15 \\
3 & 27 \\
4 & 47 \\
5 & 79 \\
6 & 99 \\
7 & 175 \\
8 & 251 \\
9 & 323 \\
10 & 411 \\
11 & 495 \\
12 & 587 \\
13 & 695 \\
14 & 915 \\
15 & 1027 \\
\hline
\end{tabular}

corresponding to two input parameters can interact to create harmonics not present originally, and, in this way, decrease the relative contribution to the output spectrum of the input parameters. Whenever several ways of defining input parameters exist, those linearly related with the output parameters will be more adequate for FAST studies.

- The input parameters should be either independent or their dependency (in form of covariances between pairs of parameters) should be modelled. The independency of the input parameters usually is an a priori assumption based on the way the parameters are selected. If an input parameter is physically related either with other input parameters or with the model forcing conditions, the partial variance corresponding to such input parameter will be unrealistic.

- The FAST technique provides the module of the sensitivity but not its sign.

- The simultaneous introduction of many parameters, some of them with low partial variance, usually attenuates the effect of the most sensitive parameters. As mentioned above, the nonlinear contributions originated by interactions of pairs of parameters generate new harmonics, decreasing the relative contribution to the output spectrum by the input parameters.

- The range of variation of the input parameters is usually a critical issue. Sensitivity results, expressed as partial variances of single parameters, can be very much affected by the selection of that range. Some degree of arbitrariness is always involved in the selection of parameters, their range of variation, and their PDF. Trials with several ranges of variation and different PDFs can help identify their effects.

\section{Brief description of the land-surface schemes}

In this study, FAST is used with the landatmosphere interactive dynamics (LAID) developed by Avissar and Mahrer (1988), the interaction soil-biosphere-atmosphere (ISBA) developed by Noilhan and Planton (1989) and the biosphere-atmosphere transfer scheme (BATS) developed by Dickinson (1984). Their formulation and degree of complexity are somewhat different. The three models were run with steady-state atmospheric conditions. LAID was integrated until steady-state was reached, as only a few iterations are needed to solve the energy balance equations for soil and canopy layers. The simplified version of LAID described in Collins and Avissar (1994) was adopted here to avoid the introduction of soil moisture in all soil layers (it originally had 13 layers) as parameters and to prevent the introduction of additional parameters (as, root distribution, porosity, percentage of sand, percentage of clay, etc.) not always independent. Furthermore, the importance of soil moisture al different depths depends both on the vertical distribution of roots and on the integration range. However, BATS and ISBA were integrated for $24 \mathrm{~h}$, as soil moisture was only left to evolve in the upper surface layer. In both squemes, soil moisture in the upper layer is steered by surface fluxes and by fixed soil moisture in the lower layer. The ISBA scheme reaches the steady-state typically before $24 \mathrm{~h}$, whereas BATS can need several days. At the equilibrium state, moisture flux in the upper boundary of the surface layer is compensated by soil moisture diffusion from the lower layer. Initial soil wetness was one of the parameters considered for the three models. Equilibrium latent and sensible heat fluxes ( $E$ and $H$, respectively) between the atmosphere and the surface were computed for each atmospheric steady-state condition, and were used as model outputs in the FAST algo- 
rithm. No precipitation of any type was considered here.

\section{1. $L A I D$}

The version of the land-atmosphere interactive dynamics (LAID) scheme used for this comparison is comprehensively described in Collins and Avissar (1994) and Avissar and Pielke (1989). The surface is considered to consist of two layers, a vegetation and a soil layer. Surface energy fluxes of latent and sensible heat are calculated from two energy budget equations, one for the vegetation and one for the soil layer. No storage of heat is allowed for the canopy. Therefore, the net radiative energy absorbed by the plant canopy is released as sensible and latent heat back to the atmosphere.

In the present study, the fourteen input parameters used with the FAST program are: roughness length $\left(Z_{\mathrm{o}}\right)$, leaf area index (lai), soil texture $(t)$, soil emissivity $\left(\varepsilon_{\mathrm{g}}\right)$, soil albedo $\left(\alpha_{\mathrm{g}}\right)$, vegetation emissivity $\left(\varepsilon_{\mathrm{v}}\right)$, vegetation albedo $\left(\alpha_{\mathrm{v}}\right)$, vegetation extinction coefficient $\left(\kappa_{\mathrm{v}}\right)$, soil surface wetness $(W)$, maximum relative stomatal conductance $\left(\mathrm{Cs}_{\max }\right)$, radiation factor for stomatal conductance $\left(R_{\mathrm{st}}\right)$, temperature factor for stomatal conductance $\left(T_{\mathrm{st}}\right)$, vapor pressure deficit factor for stomatal conductance $\left(e_{\mathrm{st}}\right)$, and soil moisture potential factor for stomatal conductance $\left(W_{\mathrm{st}}\right)$. These parameters are summarized in Table 2, and are prescribed by continuous PDFs. Most maximum and minimum values assigned were obtained from Collins and Avissar (1994). However, the soil thermal conductivity was expressed as a function of soil texture and water content (McCumber and Pielke, 1981). The textural classification of the U.S. Department of Agriculture (USDA) was used for the texture parameter (Clapp and Hornberger 1978). The discrete classification, which assigns values to the hydraulic parameters corresponding to 11 soil types was extended to the continuous domain between 1 and 11, simply by interpolating linearly between values assigned to the integers. The computation of the relative stomatal conductance introduces additional parameters (Avissar et al., 1985; Avissar and Pielke, 1989) with their respective uncertainty range. Uncertainty was allowed in the maximum stomatal conductance, and in the environmental parameters for which the relative stomatal conductance are half their maximum value. The variation range of leaf area index and roughness length was not taken as in Collins and Avissar (1994), to assign the same interval to equivalent parameters in the three models.

\section{2. $I S B A$}

The interaction soil-biosphere-atmosphere (ISBA) scheme, was developed by Noilhan and Planton (1989) (see also Bougeault et al., 1991; Braud et al., 1993; Giordani, 1993; Noilhan et al., 1993; Noilhan and Lacarrére, 1995; Mahfouf et al., 1995) and modified by Bringfelt (1996) and by Giard and Bazile (1997) for its operational implementation in the HIRLAM and ARPEGE systems, respectively. In this scheme sensible and latent fluxes are averaged according to the fractional areal share of the grid square. The whole scheme makes an efficient use of the new physiographic database created for the HIRLAM system (Bringfelt et al., 1995). The land surface scheme treats vegetation processes, such as surface canopy resistance to water transpiration and storage and evaporation of intercepted rainfall. The land part of the scheme includes a two-layer force-restore model for soil moisture and temperature. There is an additional equation for moisture stored in the canopy.

In this study, the prognostic equations for mean temperature and bulk soil moisture were not solved, thus resulting in constant mean temperature and bulk soil moisture equal to their initial value. As diurnal cycle is suppressed by prescribing environmental conditions, it seems more reasonable to keep mean temperature constant. Bulk soil moisture is kept constant to assure that some steady-state is reached when the surface soil moisture equation is integrated. Soil moisture in the surface layer $(10 \mathrm{~cm})$ reaches a steady value, typically within $24 \mathrm{~h}$ of integration.

The surface resistance is expressed by a product of a minimum value and a number of limiting factors (Jarvis, 1976; Dickinson, 1984; Jacquemin and Noilhan, 1989; Thompson et al., 1981) depending on environmental conditions (radiation, water stress, vapor pressure deficit and air temperature).

The ISBA scheme distinguishes between 2 primary and 15 secondary parameters. The 2 primary parameters refer to the dominant type of vegetation and soil texture. For each of the 11 soil texture types of the USDA classification, values 
Table 2. Land-surface parameters used for the LAID scheme as input to the FASTalgorithm; their maximum and minimum values determine the range of variability of every parameter as it is used in the analysis

\begin{tabular}{lcc}
\hline \multicolumn{1}{c}{ Parameter } & Minimum & Maximum \\
\hline soil albedo $\left(\alpha_{\mathrm{g}}\right)$ & 0.05 & 0.95 \\
soil emissivity $\left(\varepsilon_{\mathrm{g}}\right)$ & 0.80 & 0.995 \\
soil texture $(t)$ & 1.0 & 11.0 \\
vegetation albedo $\left(\alpha_{\mathrm{v}}\right)$ & 0.14 & 0.20 \\
vegetation emissivity $\left(\varepsilon_{\mathrm{v}}\right)$ & 0.90 & 0.99 \\
vegetation extinction coefficient $\left(\kappa_{\mathrm{v}}\right)$ & 0.30 & 2.30 \\
soil surface wetness $(W)$ & 0.0 & 1.0 \\
surface roughness $\left(Z_{\mathrm{o}}\right)(\mathrm{m})$ & 0.01 & 2.0 \\
leaf area index $($ lai $)$ & 0 & 6.0 \\
maximum relative conductance $\left(\mathrm{Cs}_{\mathrm{max}}\right)$ & 0.8 & 1.0 \\
temperature factor in conductance $\left(T_{\mathrm{st}}\right)(\mathrm{K})$ & $-2^{\circ} \mathrm{a}$ & $+2{ }^{\circ \mathrm{a}}$ \\
radiation factor in conductance $\left(R_{\mathrm{st}}\right)$ & $-25 \% \mathrm{~b}$ & $+25 \%{ }^{\mathrm{b}}$ \\
water vapor factor in conductance $\left(e_{\mathrm{st}}\right)$ & $-25 \% \mathrm{~b}$ & $+25 \%{ }^{\mathrm{b}}$ \\
moisture potential factor in conductance $\left(W_{\mathrm{st}}\right)$ & $-25 \%{ }^{\mathrm{b}}$ & $+25 \%{ }^{\mathrm{b}}$ \\
\hline
\end{tabular}

${ }^{\text {a }}$ The variation range is $\pm 2^{\circ}$ the model value.

b The variation range is $\pm 25 \%$ of the model value.

are assigned to each of the 8 hydraulic secondary parameters (Table 2 of Noilhan and Planton (1989) and Table A2.1 of Bringfelt (1996)). In Noilhan and Lacarrere (1995) the 8 hydraulic parameters are expressed as a function of percentage of sand and percentage of clay. The 8 hydraulic parameters consequently result into just 2 . The Wilson and Henderson-Sellers (1985) classification is used for assigning the vegetation secondary parameters to the 18 types of classified land use. For this FAST application, the parameters related to vegetation are considered independent with the exception of the soil column depth (always equal to $1 \mathrm{~m}$ ) and fraction of vegetation (always equal to 1 ).

In this analysis, the thirteen input parameters used with the FAST program are: percentage of clay $(c)$, percentage of sand $(s)$, initial soil moisture in the surface layer $\left(W_{\mathrm{s}}\right)$, initial bulk soil moisture $\left(W_{\mathrm{d}}\right)$, roughness length $\left(Z_{\mathrm{o}}\right)$, leaf area index (lai), minimum stomatal resistance $\left(\mathrm{Rs}_{\min }\right)$, photosynthetically active radiation factor for stomatal resistance $\left(R_{\mathrm{st}}\right)$, vapor pressure deficit factor for stomatal resistance $\left(e_{\mathrm{st}}\right)$, temperature factor for stomatal resistance $\left(T_{\text {st }}\right)$, soil moisture factor for stomatal resistance $\left(W_{\text {st }}\right)$, albedo $(\alpha)$ and emissivity $(\varepsilon)$. The four parameters related to stomatal resistance were not originally included in the list of the
15 secondary parameters. They have been introduced here to study their sensitivity in the stomatal resistance formulation. These four additional parameters can, in principle, be species dependent.

The maximum and minimum values assigned to the various parameters were obtained from the climate model described by Manzi and Planton (1994) and used by Bringfelt (1996) in the HIRLAM model operational implementation. The range of variation of leaf area index and roughness length is the same as in the other two models. The range of variation of minimum stomatal resistance is the same as in BATS. The 13 input parameters and their corresponding range of variation range are summarized in Table 3.

\subsection{BATS}

The version of the biosphere-atmosphere transfer scheme (BATS) used for this comparison is comprehensively described in Dickinson (1993). The current frozen version, BATS1e, includes (i) calculation of soil temperature in response to net surface heating and depending on soil heat capacity and thermal conductivity, (ii) calculation of soil moisture, evaporation, and surface and groundwater runoff, (iii) specification of vegetation cover in terms of fractional ground shading and 
Table 3. Land-surface parameters used for the ISBA scheme as input to the FASTalgorithm; their maximum and minimum values determine the range of variability of every parameter as it is used in the analysis

\begin{tabular}{|c|c|c|}
\hline Parameter & Minimum & Maximum \\
\hline$\%$ of sand $(s)$ & 10 & 100 \\
\hline$\%$ of clay $(c)$ & 10 & 100 \\
\hline surface soil wetness $\left(W_{\mathrm{s}}\right)$ & 0.0 & 1.0 \\
\hline total soil wetness $\left(W_{\mathrm{d}}\right)$ & 0.0 & 1.0 \\
\hline roughness length $\left(Z_{\mathrm{o}}\right)(\mathrm{m})$ & 0.01 & 2.0 \\
\hline leaf area index (lai) & 0.0 & 6.0 \\
\hline minimum stomatal resistance $\left(\mathrm{Rs}_{\min }\right)$ & 120.0 & 200.0 \\
\hline radiation transpiration factor $\left(R_{\mathrm{st}}\right)\left(\mathrm{W} \mathrm{m}^{-2}\right)$ & 30.0 & 100.0 \\
\hline vapor transpiration factor $\left(e_{\mathrm{st}}\right)$ & 0.0 & 0.04 \\
\hline temperature transpiration factor $\left(T_{\mathrm{st}}\right)(\mathrm{K})$ & 295.0 & 300.0 \\
\hline wetness transpiration factor $\left(W_{\mathrm{st}}\right)$ & 0.8 & 1.0 \\
\hline albedo $(\alpha)$ & 0.14 & 0.20 \\
\hline emissivity $(\varepsilon)$ & 0.90 & 0.99 \\
\hline
\end{tabular}

relative areas of transpiring and non-transpiring plant surface for different types of land-use, (iv) surface albedo in terms of soil moisture and vegetation cover, (v) plant water budget including foliage and stem water storage, intercepted precipitation, and transpiration as limited by stomatal resistance and soil dryness, and (vi) determination of foliage temperature in response to energybalance requirements and consequent fluxes of heat and moisture from the foliage to the canopy air.

The surface resistance is expressed by a product of a minimum value and a number of limiting factors (Jarvis, 1976) depending on environmental conditions (radiation, seasonal temperature and vapor pressure deficit).

For this FAST application, subsurface temperature, soil water in the rooting layer and soil water in the total soil column are kept constant along the integration. Soil water is only integrated for the surface upper layer (around $10 \mathrm{~cm}$ ). The steady-state could not be reached after $24 \mathrm{~h}$ due to the slow evolving soil water, even in the thin upper layer. Longer integrations change the relative role played by soil water in the upper surface and rooting layers.

BATS uses 18 distinct vegetation types (Table 1 in Dickinson (1993)) when coupled to the National Center for Atmospheric Research Community Climate Model (NCAR CCM) to represent different land uses. There are 16 parameters (see
Table 3b in Henderson-Sellers (1993)) associated with each of these 18 classes. It uses 12 soil textural classes as well as 8 color classes. There are 6 soil parameters associated with each texture class and 4 reflectances associated with each color class (see Table 3 in Dickinson (1993)). Thus, to use this scheme a total of $26(16+6+4)$ parameters must be specified for each grid point. The possibility of changing independently all 26 parameters could lead to some unrealistic combinations of parameters, not always existing in nature. To avoid such inconsistencies as much as possible, the following assumptions were made.

(1) The six soil parameters belonging to the different textures were not allowed to vary within each of the textural classes. Thus, only one parameter was used to characterize a single class. This parameter ranges continuously between 1 and 12 and it is obtained by linear interpolation to the nearest soil parameters for the non-integers values of textural class. The textural class, considered as a continuous parameter, has no physical significance but it allows to estimate the sensitivity of texture.

(2) The same procedure was adopted for color class. One continuous parameter, varying from 1 to 8 , was defined using the color class table. Linear interpolations between the nearest color classes were computed for non-integers values of the parameter. Texture and color parameters range between the values proposed by Wilson (1984) 
using the Food and Agriculture Organization Soil Map of the World (FAO/UNESCO, 1974).

(3) Fixed values are assigned to the following vegetation parameters. (i) Depth of the three soil layers $(0.1,1$ and $10 \mathrm{~m}$, respectively). They are not independent of initial soil water depth, which is the soil water variable used in BATS. (ii) Maximum fractional vegetation cover (1). It is not independent of leaf area index (lai); (iii) Difference between maximum fractional vegetation cover and cover at temperature of $269 \mathrm{~K}$. The seasonal dependency of vegetation cover is eliminated (fractional cover is fixed to 1). (iv) Rooting ratio (0.8). It changes the role of initial soil water at different layers. (v) Minimum lai. LAI is fixed to its maximum value. (vi) Inverse square root of the leaf dimension (5). It is not independent of lai. (vii) Zero plane displacement height $(d)$ of vegetation $(0)$. It is strongly correlated with roughness length $\left(Z_{\mathrm{o}}\right)$. In fact the simple relation $d / z_{0} \sim 2 / 3$ seems to be fairly representative of many natural vegetated surfaces (Garratt, 1992).

(4) Two parameters not used as such in the scheme were allowed to vary as well, to study their sensitivity as compared to the other two schemes. These parameters, which have constant value assigned in BATS, are the vapor pressure deficit factor and the temperature factor of the stomatal resistance.

In summary, the following 13 input parameters were used with FAST: surface soil water depth $\left(W_{\mathrm{s}}\right)$, soil water depth in the rooting zone $\left(W_{\mathrm{r}}\right)$, texture $(t)$, color $(c)$, roughness length $\left(Z_{\mathrm{o}}\right)$, minimum stomatal resistance $\left(\mathrm{Rs}_{\min }\right)$, maximum leaf area index (lai), stem area index (sai), vapor pressure deficit factor for the stomatal resistance $\left(e_{\mathrm{st}}\right)$, temperature factor for the stomatal resistance $\left(T_{\text {st }}\right)$, vegetation reflectance of visible wavelengths $\left(\alpha_{\mathrm{vis}}\right)$, vegetation reflectance of infrared wavelengths $\left(\alpha_{\text {ir }}\right)$ and factor describing the sensitivity of the stomatal resistance to the amount of photosynthetically active solar radiation $\left(R_{\mathrm{st}}\right)$. The maximum and minimum values assigned to these parameters were obtained either from published tables (Dickinson, 1993) or from the corresponding values used in the other schemes (when parameters are comparable). As the role of the reflectance turned out to be very small, no attempt was made to model the covariance between infrared and visible reflectances. The 13 input parameters and their corresponding variation range are summarized in Table 4.

\section{Numerical experiments}

The number of selected input parameters was 14 for LAID and 13 for ISBA and BATS, which requires 915, 695, and 695 model runs for FAST, respectively (Table 1). Table 5 summarizes the set of prescribed environmental conditions. Five atmospheric variables were considered: temperature $\left(T_{\mathrm{a}}\right)$, relative humidity $\left(R H_{\mathrm{a}}\right)$, wind speed $\left(W_{\mathrm{a}}\right)$, solar radiation $\left(R_{\mathrm{s}}\right)$, and atmospheric thermal radiation $\left(R_{\mathrm{a}}\right)$. Three values were used for each variable, producing a total of $3^{5}=243$ possible combinations of these atmospheric conditions. Three different PDFs were used for each of the model parameters: uniform, normal, and lognormal. Multiplying the number of model runs required by FAST, by the number of environmental conditions, and by the number of PDFs computed, it turns out that the total number of integrations was $915 \times 243 \times 3=667035$ for LAID and $695 \times 243 \times 3=527505$ for ISBA and BATS.

With the uniform distribution for all of the input parameters, all values within the defined range are given equal probability.

The PDF for the normal distribution is

$p(x)=\frac{1}{\alpha \sqrt{2 \pi}} \exp \left[-\frac{1}{2}\left(\frac{x-\mu}{\sigma}\right)^{2}\right]$

where $\mu$ and $\sigma^{2}$ are the mean and the variance of the distribution, respectively. The mean was set to be the midpoint between the maximum $\left(x_{\max }\right)$ and the minimum $\left(x_{\min }\right)$ value for each parameter. The standard deviation was defined as

$\sigma=\left(x_{\max }-x_{\min }\right) / \sigma$.

Since the normal distribution is defined as a continuous function in the range $-\infty$ to $+\infty$, the chosen mean and standard deviation satisfies the condition that $98 \%$ of the PDF is contained within the range of each parameter.

The PDF of the lognormal distribution is

$p(x)=\frac{1}{s \sqrt{2 \pi} x} \exp \left[-\frac{1}{2}\left(\frac{\ln x-M}{s}\right)^{2}\right]$

where $M$ and $s^{2}$ are the mean and variance of the normally distributed "ln $x$ " variable, respectively. 
Table 4. Land-surface parameters used for the BATS scheme as input to the FASTalgorithm; their maximum and minimum values determine the range of variability of every parameter as it is used in the analysis

\begin{tabular}{lcc}
\hline \multicolumn{1}{c}{ Parameter } & Minimum & Maximum \\
\hline surface soil water $\left(W_{\mathrm{s}}\right)(\mathrm{m})$ & 0.0 & 0.06 \\
root zone soil water $\left(W_{\mathrm{r}}\right)(\mathrm{m})$ & 0.0 & 0.66 \\
soil texture $(t)$ & 1 & 12 \\
soil color $(c)$ & 1 & 8 \\
roughness length $\left(Z_{\mathrm{o}}\right)(\mathrm{m})$ & 0.01 & 2.0 \\
minimum stomatal resistance $\left(\mathrm{Rs}_{\text {min }}\right)$ & 120.0 & 200.0 \\
leaf area index $($ lai $)$ & 0.0 & 6.0 \\
stem area index $($ sai $)$ & 0.0 & 4.0 \\
vapor transpiration factor $\left(e_{\text {st }}\right)$ & 0.0 & 0.04 \\
temperature transpiration factor $\left(T_{\text {st }}\right)(\mathrm{K})$ & 295.0 & 300.0 \\
light sensitivity factor $\left(R_{\text {st }}\right)$ & 0.02 & 0.06 \\
reflectance IR $\left(\alpha_{\text {ir }}\right)$ & 0.18 & 0.34 \\
reflectance VIS $\left(\alpha_{\text {vis }}\right)$ & 0.04 & 0.20 \\
\hline
\end{tabular}

Table 5. Input values of prescribed environmental variables used for the experiments

\begin{tabular}{lccc}
\hline \multicolumn{1}{c}{ Parameter } & $\begin{array}{c}\text { Minimum } \\
(\mathrm{m})\end{array}$ & $\begin{array}{c}\text { Intermediate } \\
(\mathrm{i})\end{array}$ & $\begin{array}{c}\text { Maximum } \\
(\mathrm{M})\end{array}$ \\
\hline wind speed $\left(\mathrm{ms}^{-1}\right)$ & 2.0 & 4.0 & 6.0 \\
relative humidity (\%) & 20 & 50 & 80 \\
air temperature $(\mathrm{K})$ & 283 & 293 & 303 \\
solar radiation $\left(\mathrm{W} \mathrm{m}{ }^{-2}\right)$ & 0 & 400 & 800 \\
atmospheric radiation $\left(\mathrm{W} \mathrm{m}^{-2}\right)$ & 250 & 300 & 350 \\
\hline
\end{tabular}

Its mean is given by

$e^{M+s^{2} / 2}=x_{\min }+a\left(x_{\max }-x_{\min }\right)$

and its mode is defined as

$e^{M-s^{2}}=x_{\min }+b\left(x_{\max }-x_{\min }\right)$

where $a$ and $b$ are empirical constants. The adopted value for these constants were 0.4 and 0.3 , respectively.

In the first set of experiments, it was assumed that vegetation covers $100 \%$ of the simulated domain. In the second set, bare soil was assumed. Thus, in this second set, evaporation was the only mechanism extracting water from the soil. All parameters related to vegetation were eliminated and, consequently, the total number of parameters was drastically reduced. Finally, the last set of experiments, performed with BATS only, explored which environmental variables are more important for land-surface processes. For each of the 15 vegetation types available in the BATS scheme, the partial variances corresponding to the forcing atmospheric variables were computed.

\section{Results}

As we are mainly interested in drawing common behaviour patterns from the three considered schemes, the relative importance of parameters was considered on average for the different environmental conditions. The rationale for designing our numerical experiment and looking at the results this way was to find the minimum numbers of parameters able to explain most of the variance in surface heat fluxes.

\subsection{Latent heat flux}

Fig. 1 provides the partial variance of latent heat flux for each of the input surface parameters 


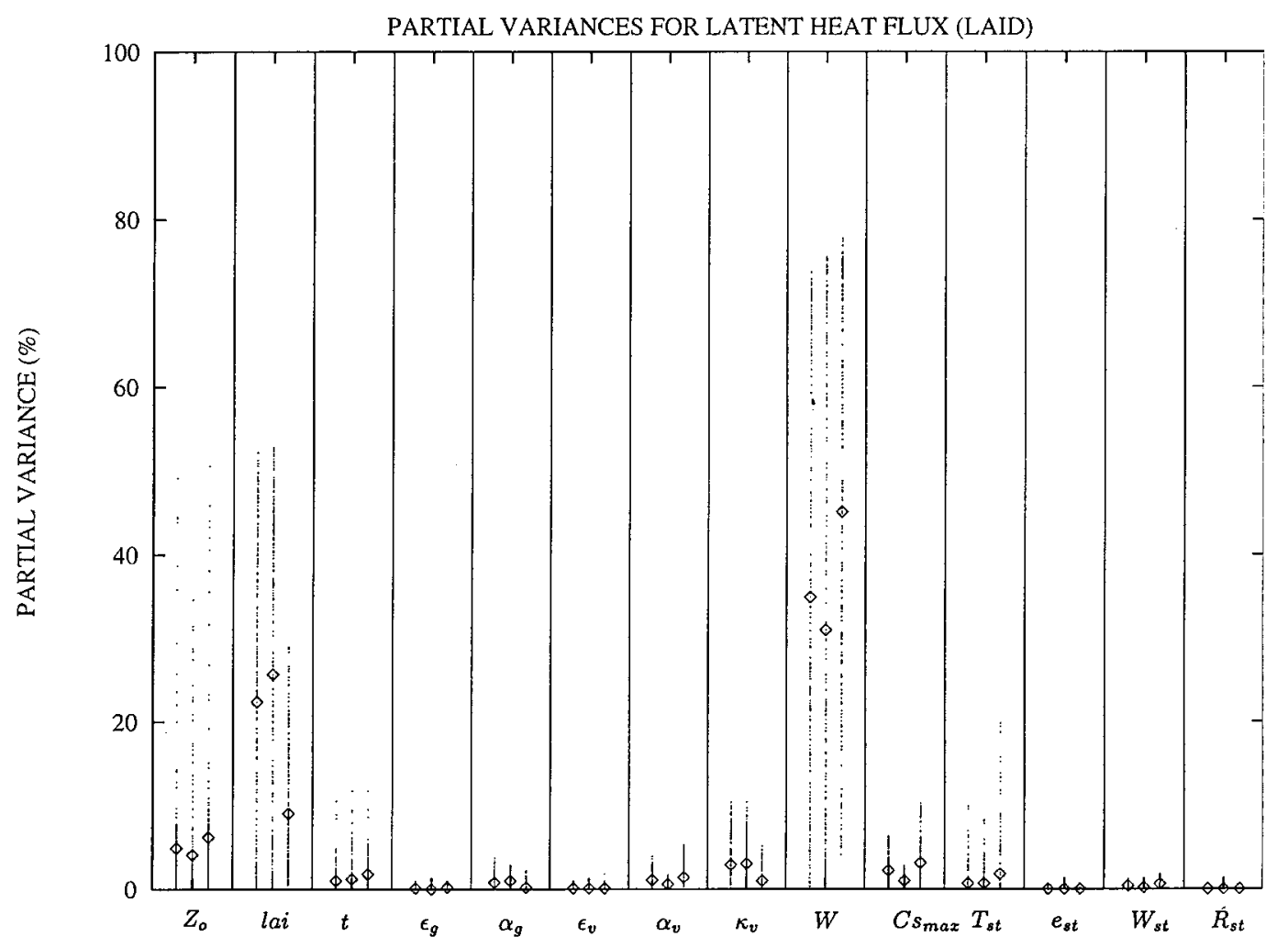

Fig. 1. Partial variances of latent heat flux obtained from the FAST analysis using the LAID scheme in a fully vegetated domain. The 3 distributions described in Section 4 (see text for details) were used to represent the variability of roughness length $\left(Z_{\mathrm{o}}\right)$, leaf area index (lai), soil texture $(t)$, soil emissivity $\left(\varepsilon_{\mathrm{g}}\right)$, soil albedo $\left(\alpha_{\mathrm{g}}\right)$, vegetation emissivity $\left(\varepsilon_{\mathrm{v}}\right)$, vegetation albedo $\left(\alpha_{\mathrm{v}}\right)$, extinction coefficient $\left(\kappa_{\mathrm{v}}\right)$, soil wetness $(W)$, maximum relative stomatal conductance $\left(\mathrm{Cs}_{\max }\right)$, temperature coefficient in relative stomatal conductance $\left(T_{\mathrm{st}}\right)$, water vapor deficit coefficient in relative stomatal conductance $\left(e_{\text {st }}\right)$, soil moisture coefficient in relative stomatal conductance $\left(W_{\text {st }}\right)$, solar radiation coefficient in relative stomatal conductance $\left(R_{\mathrm{st}}\right)$.

used with the LAID scheme. The simulated domain was assumed to be completely covered with vegetation. The points along each line represent the partial variances obtained for the various sets of environmental conditions, and the diamonds represent the mean partial variances. Each series of points corresponds to different distribution of input parameters, namely, from left to right: lognormal, uniform and normal (see Section 4).

One fact is first noticeable: No large differences appear among the three distributions. This similarity was already pointed out by Collins and Avissar (1994) and by Liu and Avissar (1996). It corroborates the robustness of the results, since the selection of the PDFs is somewhat arbitrary.
The highest partial variance is by far contributed by the soil wetness $(W)$, with values well scattered for different environmental conditions. This is true for almost all atmospheric conditions. Leaf area index (lai) is another important parameter mainly in buoyant situations, as leaf transpiration contributes mostly to latent heat flux. The third important parameter is the roughness length $\left(Z_{\mathrm{o}}\right)$. High partial variance is associated with stable stratification, whereas the scheme is not sensitive to this parameter in unstable buoyant conditions. Two other plant parameters, the extinction coefficient $\left(\kappa_{\mathrm{v}}\right)$ and the maximum relative conductance $\left(\mathrm{Cs}_{\max }\right)$, have a marginal importance, again in buoyant conditions. The other parameters have virtually no impact on the surface 
heat fluxes under the environmental conditions considered here, for the selected parameter ranges.

Results obtained by Collins and Avissar (1994) for fully vegetated terrain demonstrate that most of the variance of surface heat fluxes may be described by the distributions of relative stomatal conductance and surface roughness. If relative stomatal conductance is parameterized as a function of the environmental variables, as was done here, then it appears that soil wetness and leaf area index inherit most of the sensitivity in landsurface processes.

Fig. 2 shows the partial variance of latent for each of the input parameters used with the ISBA scheme. Results for the simulated domain fully covered with vegetation are basically similar to those obtained with LAID. Indeed, bulk soil wetness $\left(W_{\mathrm{d}}\right)$, leaf area index (lai), and roughness length $\left(Z_{\mathrm{o}}\right)$ also explain most of the variance. Two other vegetation parameters, namely, the minimum stomatal resistance $\left(\mathrm{Rs}_{\min }\right)$ and the water vapor deficit factor for the stomatal resistance $\left(e_{\mathrm{st}}\right)$, share the rest of the variance for the latent heat flux.

Fig. 3 represents the partial variance of latent heat fluxes for each of the input parameters used with the BATS scheme. The results obtained with this scheme for the simulated domain fully covered with vegetation are similar to those obtained with LAID and ISBA, except that here soil water is distributed between the surface $\left(W_{\mathrm{s}}\right)$ and the rooting layer $\left(W_{\mathrm{r}}\right)$. As in ISBA, the water vapor deficit factor for the stomatal resistance $\left(e_{\text {st }}\right)$ shows a none negligible partial variance for the latent heat flux. However, what is distinctive here is the significant partial variance for texture $(t)$. This fact

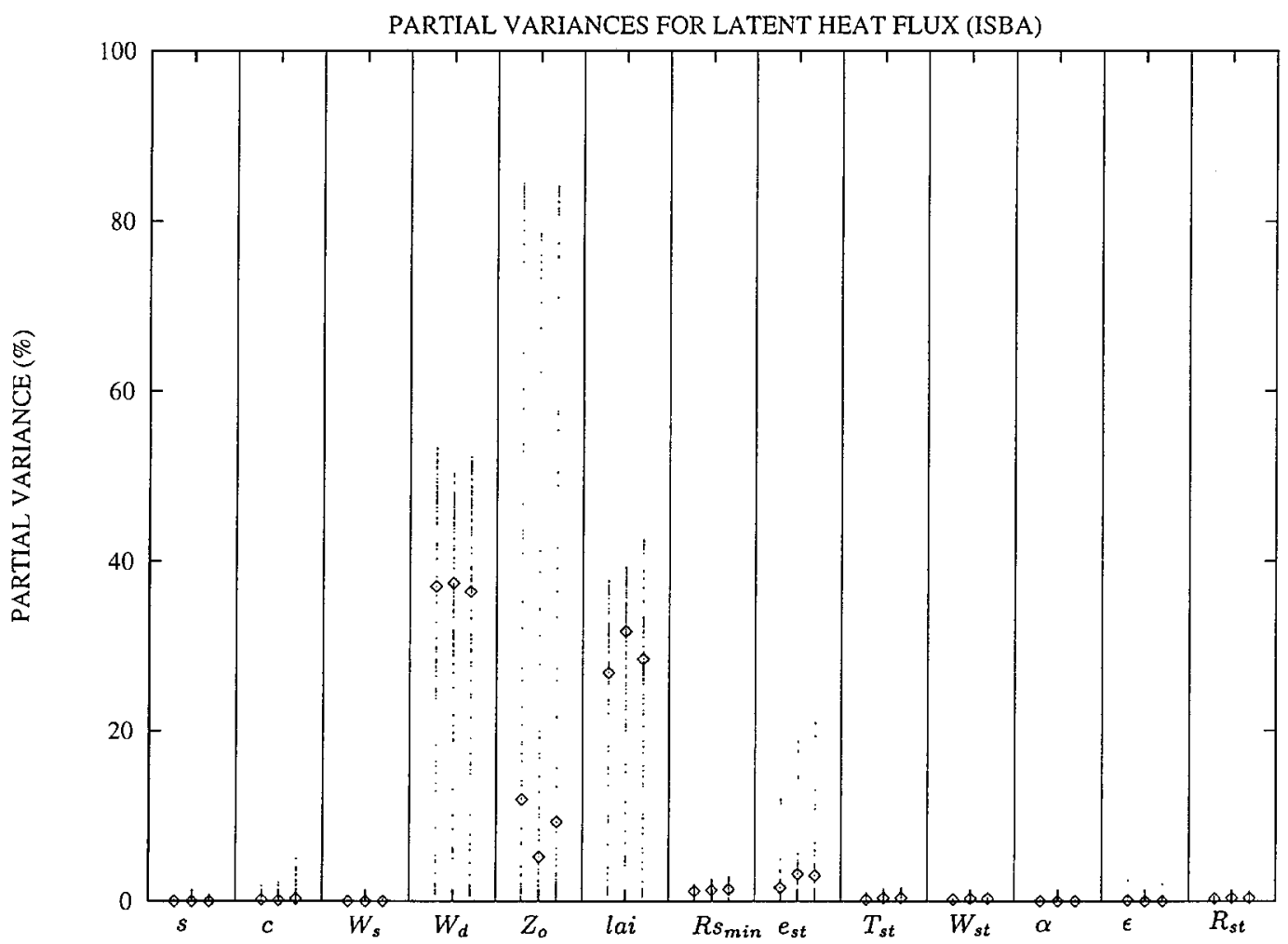

Fig. 2. Same as Fig. 1, but using the ISBA scheme with percentage of sand (s), $\%$ of clay $(c)$, superficial soil moisture $\left(W_{\mathrm{s}}\right)$, total soil moisture $\left(W_{\mathrm{d}}\right)$, leaf area index (lai), roughness length $\left(Z_{\mathrm{o}}\right)$, minimum stomatal resistance $\left(\mathrm{Rs}_{\min }\right)$, water vapor deficit coefficient in relative stomatal resistance $\left(e_{\mathrm{st}}\right)$, temperature coefficient in stomatal resistance $\left(T_{\mathrm{st}}\right)$, soil moisture coefficient in stomatal resistance $\left(W_{\mathrm{st}}\right)$, albedo $(\alpha)$, emissivity $(\varepsilon)$, solar radiation coefficient in stomatal resistance $\left(R_{\mathrm{st}}\right)$.

Tellus 50A (1998), 3 


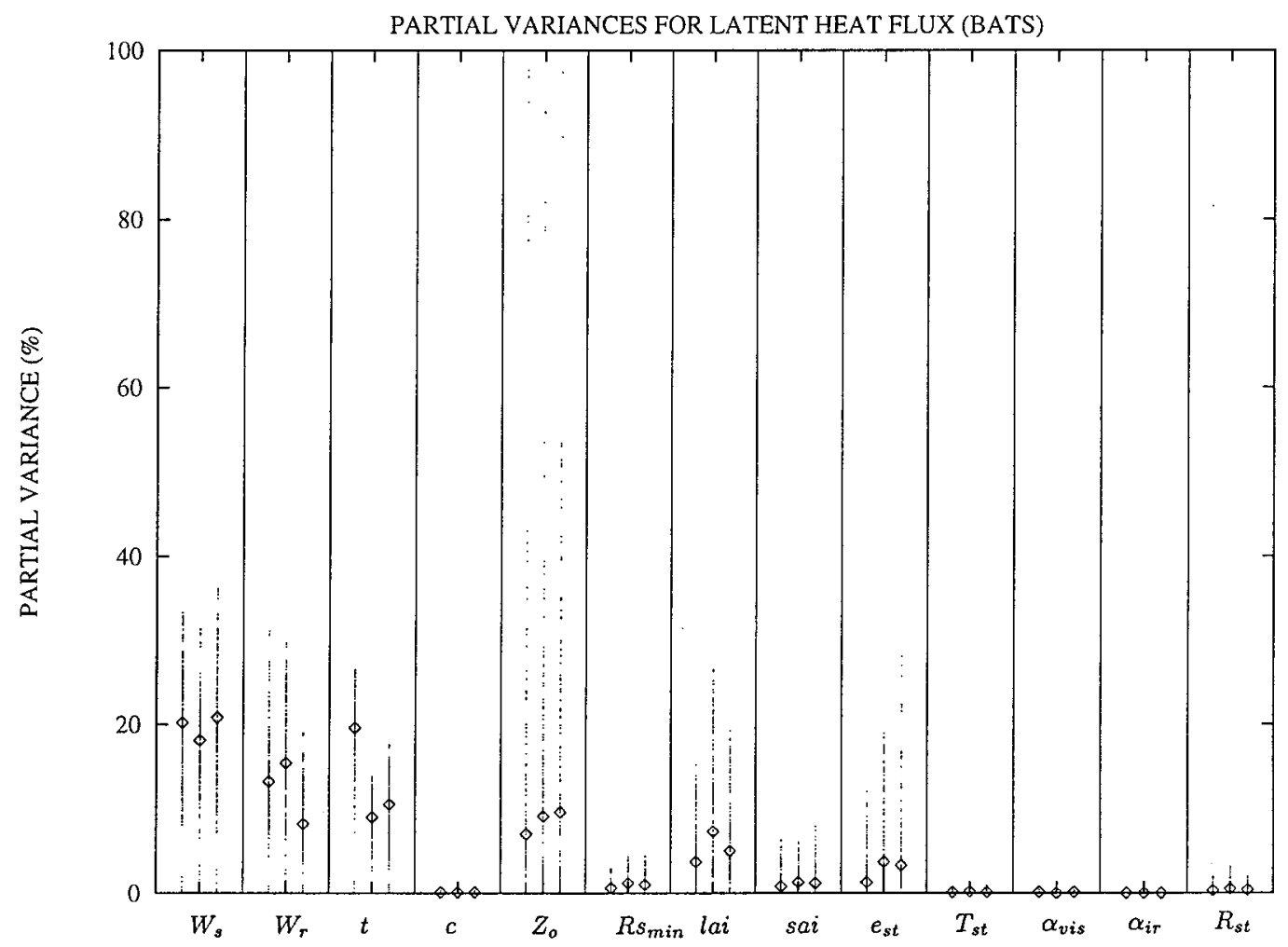

Fig. 3. Same as Fig. 1, but using the BATS scheme with water in the superficial layer $\left(W_{\mathrm{s}}\right)$, water in the rooting layer $\left(W_{\mathrm{r}}\right)$, soil texture $(t)$, soil color $(c)$, roughness length $\left(Z_{\mathrm{o}}\right)$, minimum stomatal resistance $\left(\mathrm{Rs}_{\min }\right)$, leaf area index $($ lai $)$, stem area index (sai), water vapor deficit coefficient in stomatal resistance $\left(e_{\mathrm{st}}\right)$, temperature coefficient in stomatal resistance $\left(T_{\mathrm{st}}\right)$, visible reflectance of vegetation $\left(\alpha_{\mathrm{vis}}\right)$, infrared reflectance of vegetation $\left(\alpha_{\mathrm{ir}}\right)$, light sensitivity coefficient in stomatal resistance $\left(R_{\mathrm{st}}\right)$.

was already pointed out by Wilson et al. (1987) for the case of tundra vegetation. Texture partial variance shows differences among the three distributions, reaching higher values for the lognormal distribution, which gives more weight to the sandy textures.

The previous BATS results, obtained with a root system having $80 \%$ of roots in the upper surface layer, give to moisture in the surface layer predominancy over water in the rooting layer. Such tendency is reversed either by distributing roots predominantly in the rooting layer, or by integrating over longer periods. Several days of integration allow the slowly evolving surface soil water to reach some equilibrium determined by soil water in the rooting zone, and by atmospheric conditions. In both cases, i.e., longer integrations or less roots in the upper layer, water in the rooting layer becomes more relevant than water in the surface layer.

Using the factorial method with the BATS scheme, Henderson-Sellers (1993) obtained results consistent with ours, considering the differences of both approaches. She found that the most important are vegetation roughness length, soil porosity, and the light sensitivity factor and, to a lesser extent, soil and vegetation reflectances. It must be stressed that her results were obtained for long simulation periods, which were independent of the initial conditions and, therefore, precluded the use of initial soil water as a parameter. Furthermore, the procedure used to assign values to the parameter ranges, based on the upper and lower quartile values for each of the BATS variables, was somewhat arbitrary, and excluded parameters as important as the maximum leaf area index and 
the minimum stomatal resistance. Finally, the light sensitivity factor and the minimum leaf area index were the only variables appearing in her computation of the stomatal resistance. Consequently, she found that roughness length, a parameter related to soil texture (porosity) and a parameter related to the stomatal resistance (light sensitivity factor) were the predominant parameters. By contrast, our short integrations $(24 \mathrm{~h})$ are dependent on the initial soil water content, and the leaf area index is allowed to vary in a broad interval.

\subsection{Sensible heat flux}

Fig. 4 represents the partial variance of sensible heat flux for each of the input surface parameters used with the ISBA scheme. It is noticeable that important parameters are roughly the same for sensible and latent heat (Collins and Avissar, 1994).

As surface parameters affect mainly the partitioning of the net radiative energy between latent and sensible heat, usually changes will appear simultaneously in both surface fluxes, but with reverse sign.

The distribution of partial variance changes now slightly in comparison with latent heat flux . The average relative importance of soil wetness $(W)$ and leaf area index (lai) decreases, and the average partial variance of roughness length $\left(Z_{\mathrm{o}}\right)$ increases. Again, the impact of roughness is mostly significant under stable conditions, but its partial variance is close to zero during buoyant conditions. Soil wetness and leaf area index share most of the partial variance in unstable buoyant conditions. Three vegetation parameters, namely, the extinction coefficient $\left(\kappa_{\mathrm{v}}\right)$, the maximum relative conductance $\left(\mathrm{Cs}_{\max }\right)$, and the temperature factor for the relative stomatal conductance $\left(T_{\mathrm{st}}\right)$, and the soil texture share the rest of the variance. Noticeable differences are found between the three distributions, e.g., the 3 additional vegetation parameters are almost irrelevant for the uniform distribution. The roughness length partial variances for

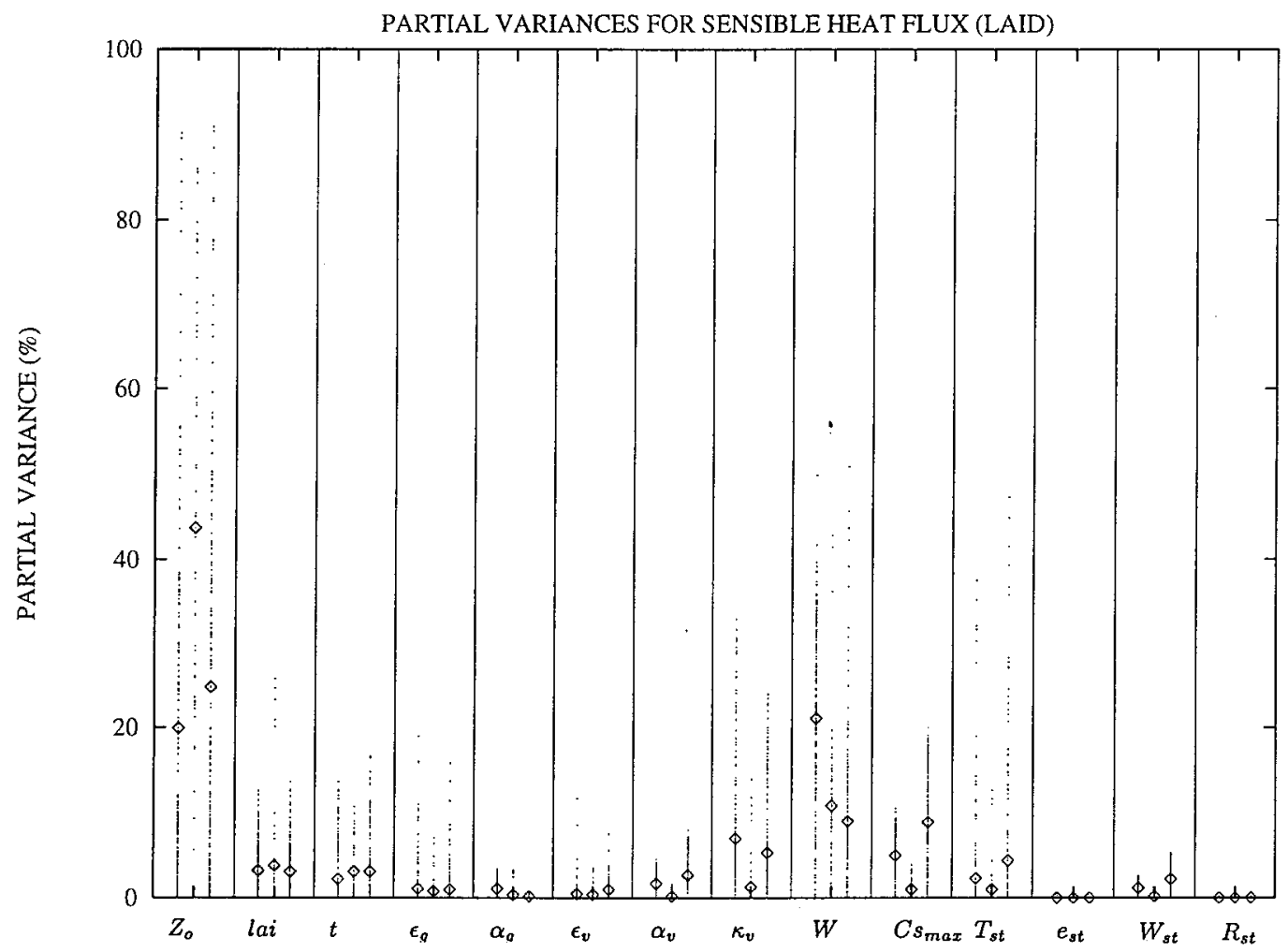

Fig. 4. Same as Fig. 1, but for sensible heat flux.

Tellus 50A (1998), 3 
the uniform distribution are more spread out, with higher average values, suggesting that the greater probability of the extreme values for parameters with a uniform distribution tends to give more importance to the roughness length and less to the other vegetation parameters.

Fig. 5 shows the partial variance of sensible heat flux for each of the input parameters used with the ISBA scheme. Results are basically similar to those obtained with LAID. Indeed, soil wetness, leaf area index, and roughness length also explain most of the variance. Two other vegetation parameters, namely, the minimum stomatal resistance and the water vapor deficit factor for the stomatal resistance, share the rest of the variance for the latent heat flux. The emissivity partial variance is significant at night for the sensible heat flux. The very simplified treatment of the canopy layer in ISBA, without any energy budget equation associated with it, seems to be the source of this excessive partial variance.

Fig. 6 provides the partial variance sensible heat flux for each of the input parameters used with the BATS scheme. The results obtained with this scheme for the simulated domain fully covered with vegetation are similar to those obtained with LAID and ISBA, except that here soil water is distributed between the surface and the rooting layer.

\subsection{Case of bare soil}

For the bare soil case using the LAID scheme, soil moisture, followed by roughness length and texture, are the most important parameters for both heat fluxes. Emissivity and albedo are only marginal on average. Soil albedo is far less important than in Collins and Avissar (1994), due to the smaller variation range selected here, to avoid any type of snow or ice albedo.

Again, soil moisture, roughness length, and texture again carry most of the variance for both surface heat fluxes, when the ISBA scheme is used.

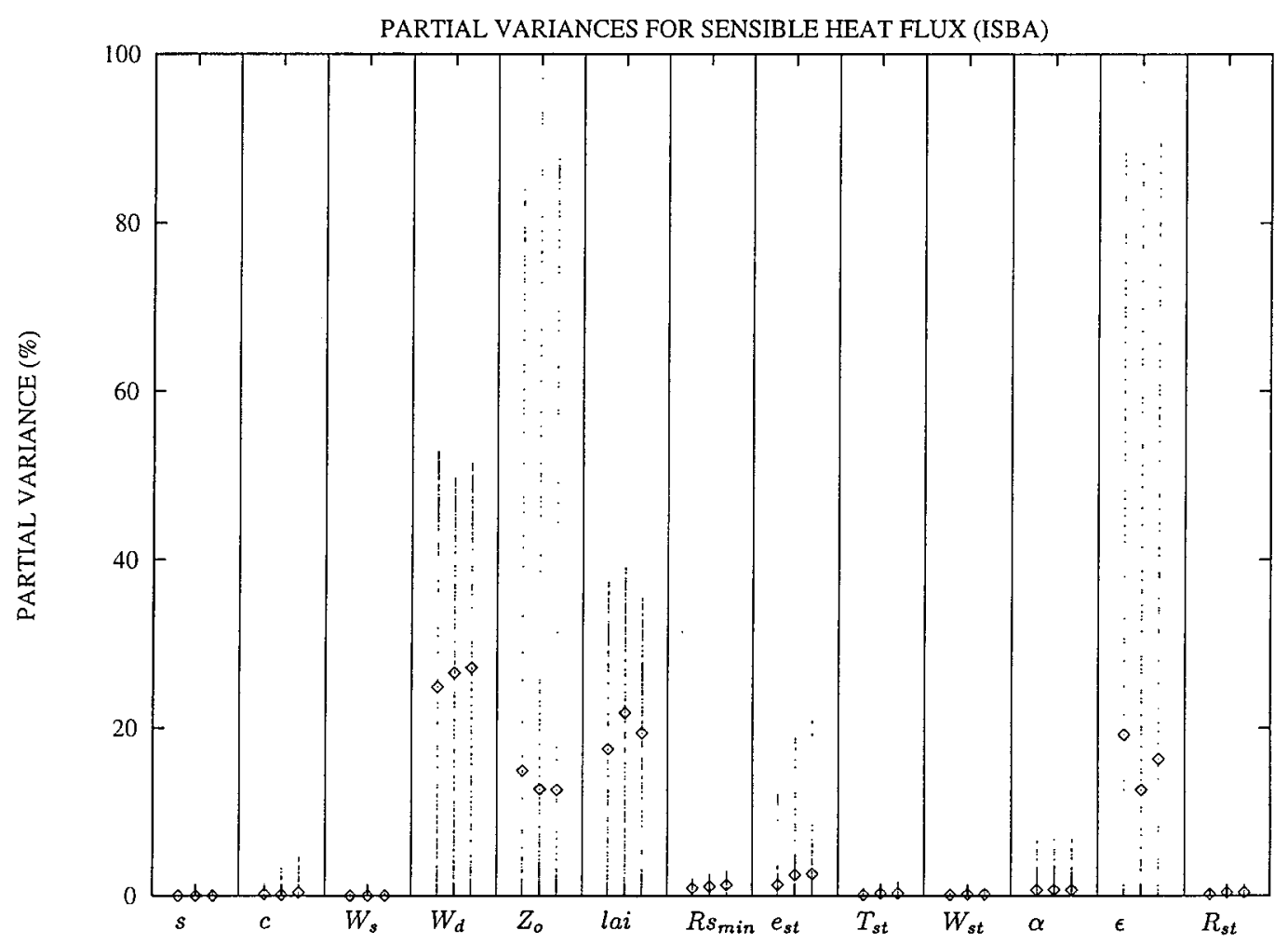

Fig. 5. Same as Fig. 2, but for sensible heat flux. 


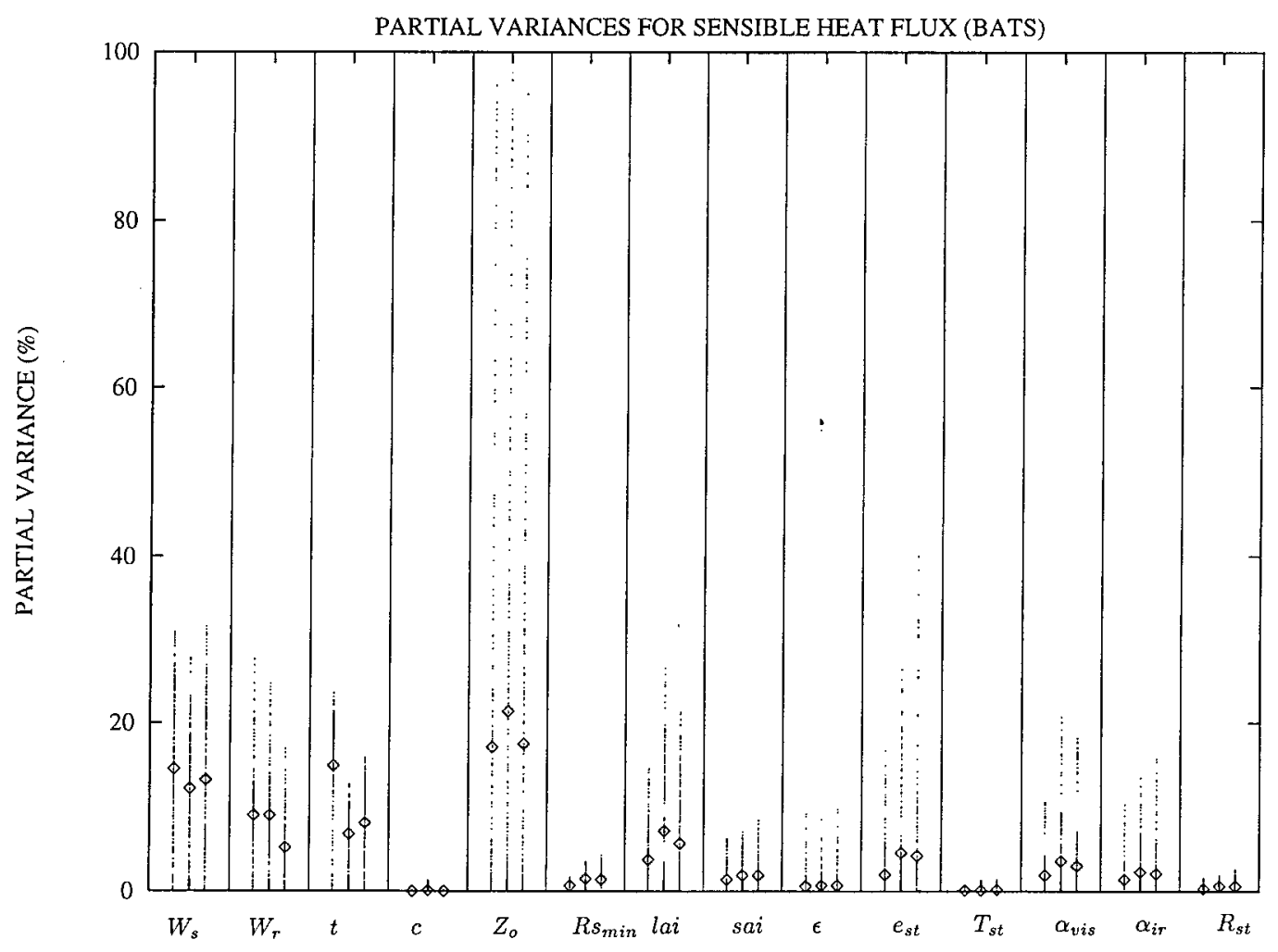

Fig. 6. Same as Fig. 3, but for sensible heat flux.

Soil texture parameters show higher partial variance for sensible heat flux.

Results using the BATS scheme in case of bare soil show sensitivity mostly to soil water content mainly in the surface layer. Texture is the second most important parameter, consistently with the vegetated case. Roughness length and color are hardly relevant for both latent and sensible heat fluxes.

\subsection{Importance of environmental variables}

The FAST technique was also applied for various environmental conditions ranging between the maximum and minimum values given in Table 5, and using the BATS model. An intermediate value was adopted for the soil color (6) and soil texture (7). The vegetation parameters were fixed (corresponding to each of the vegetation types described in (Dickinson, 1993)). Soil water content was also fixed: initial water content in the superficial layer and in the rooting zone layer was 50 and $500 \mathrm{~mm}$, respectively. Figs. 7 and 8 provide the partial variance of latent and sensible heat fluxes obtained for the different cases, respectively. Each point appearing in those figures refers to each of the 15 vegetation types considered in the BATS scheme (ice and water excluded), and the three columns for each parameter are for the three different PDFs. The vegetation types appear to be grouped in three categories: low vegetation (type 1, 2, 7, 9, $10,11,13,16$, and 17), forest (type $3,4,5,6$, and 18) and bare ground (type 8). When there is enough water in the ground, the most relevant parameter for sensible heat flux is solar radiation, followed by air temperature. This is not really surprising, given that solar radiation is the main source of energy, which is redistributed into latent and sensible heat fluxes. Temperature, as already mentioned, determines the atmospheric surface layer stability and, consequently, the magnitude of the heat fluxes to the atmosphere. Fig. 7 shows 


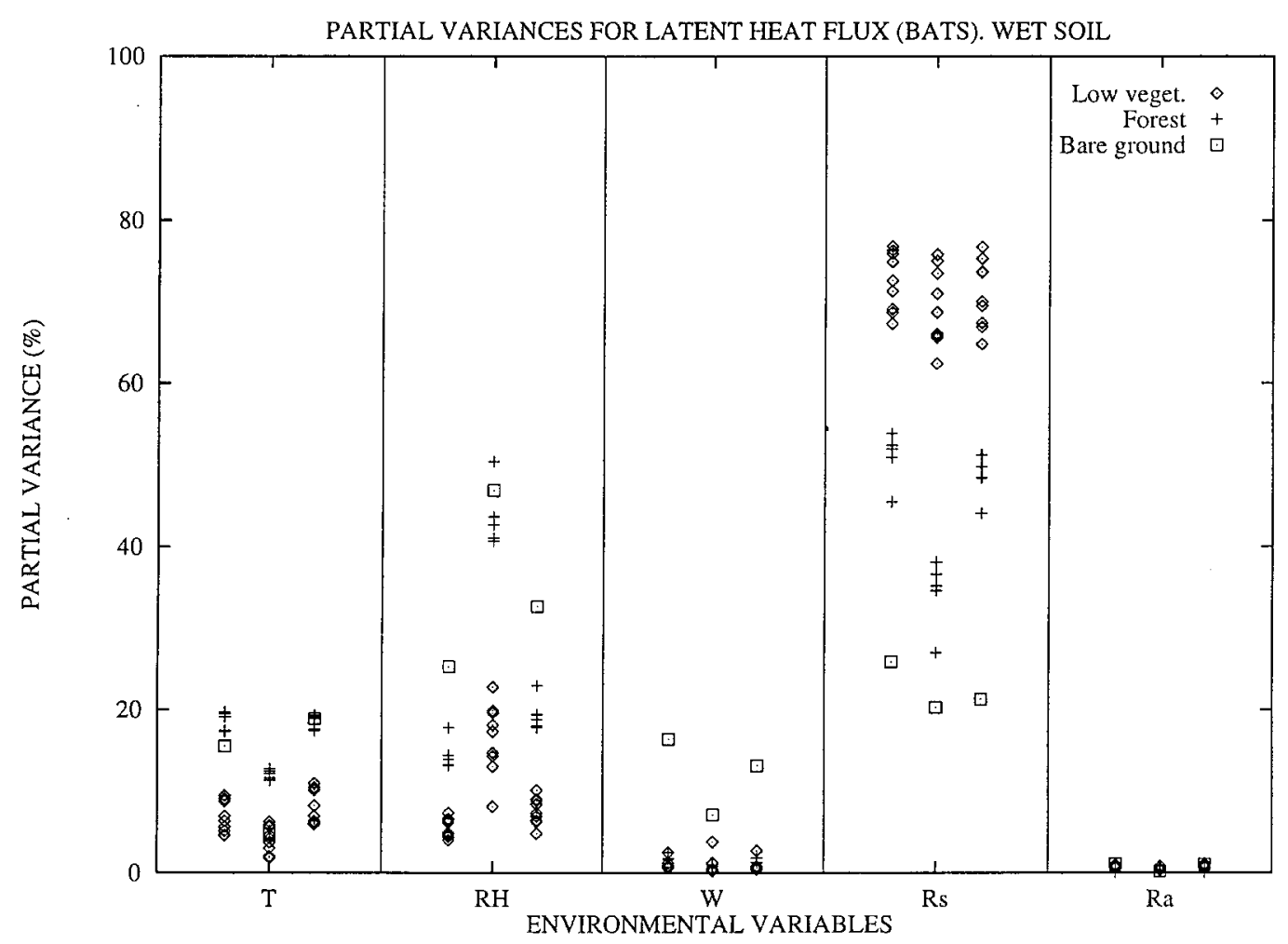

Fig. 7. Partial variances of latent heat flux obtained from the FAST analysis using the BATS scheme. Environmental variables (temperature $(\mathrm{T})$, relative humidity $(\mathrm{RH})$, wind $(\mathrm{W})$, solar radiation (Rs) and atmospheric radiation (Ra)). are now the input parameters. Computations are carried out for each of the species contemplated in the BATS scheme. For soil color (6) and soil texture (7) an intermediate value were chosen. Initial water content in the superficial layer and in the rooting zone layer was 50 and $500 \mathrm{~mm}$, respectively.

that for the latent heat flux, relative humidity is also relevant, but much less than solar radiation. In bare ground, water can be extracted only through the surface. Thus, when the upper layer is dry, most of the energy received at the ground surface is converted into sensible heat, even if the deeper soil layers are wet. Results show that, for latent heat flux, the role of solar radiation, relative humidity, temperature, and wind are about similarly important.

This set of experiments was carried out using the environmental conditions appearing in Table 5. It is well acknowledged, as it has already been stressed in the previous seccions, that soil water content is extremely important for the variation in the Bowen ratio. Consequently, precipitation, as main source of soil moisture, would have played a paramount role if it would have been included among the environmental variables. However, we have preferred along this work to consider environmental forcing without precipitation. Otherwise, the importance of the initial soil moisture considered as parameter would have been masked. Furthermore, the role of total precipitation can change depending on its intensity along the integration period.

\section{Conclusions}

The three land-surface processes schemes considered in this study seem to be sensitive to approximately the same set of parameters. Soil wetness is the most important parameter in controlling surface heat fluxes. The amount of water in the soil plays a crucial role in the redistribution 


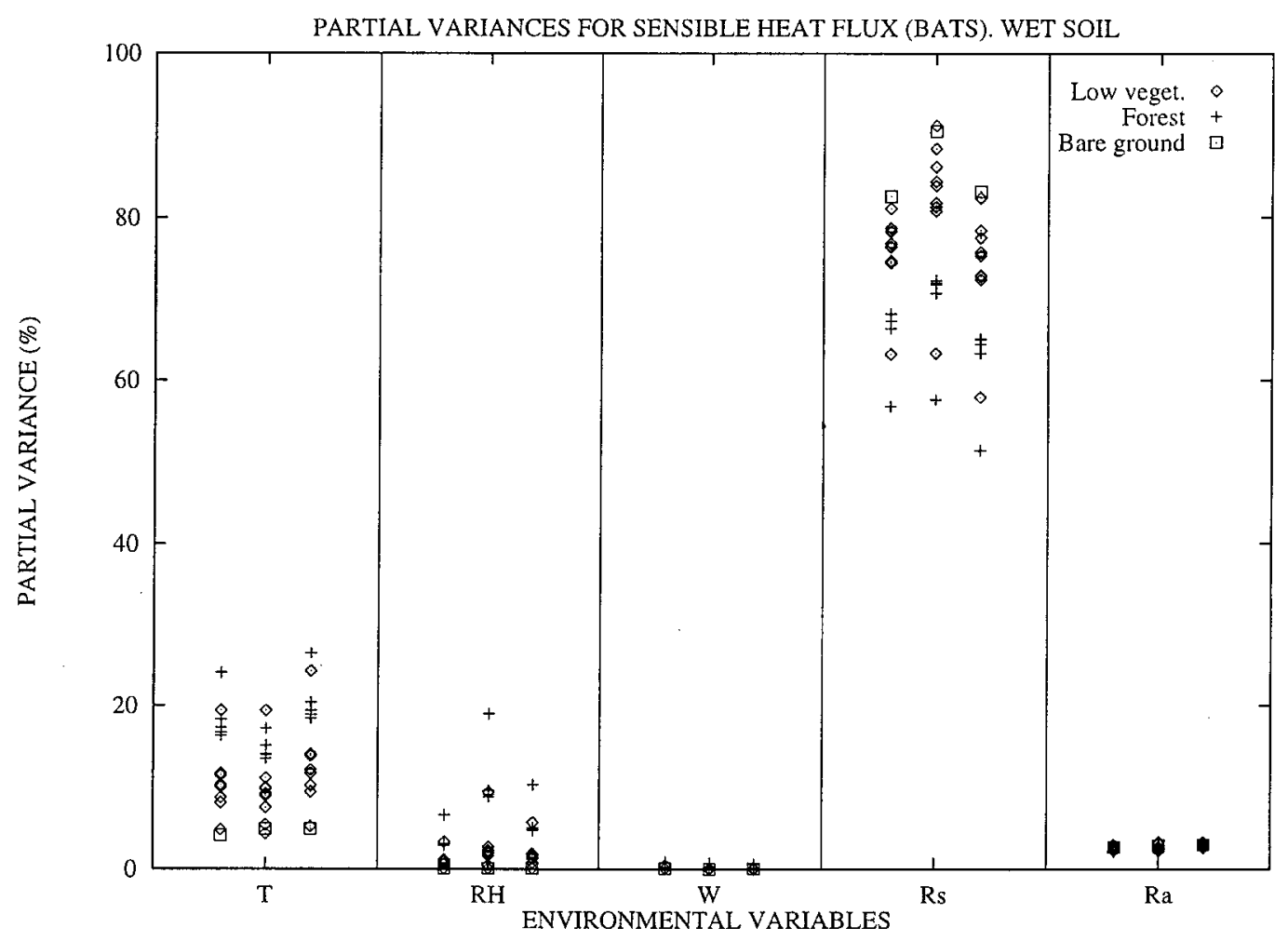

Fig. 8. Same as Fig. 7, but for sensible heat flux.

of energy into the atmosphere, either as sensible heat, or as latent heat. Roughness length controls mechanical stress and, as a result, turbulent exchanges with the atmosphere. Its role is mostly important under stable conditions, when buoyancy is small or non-existant. Vegetation parameters, mostly leaf area index (lai), constrain the vegetation response. However, the stomatal mechanism is mainly controlled by environmental conditions, including soil moisture. Assuming optimal atmospheric conditions and soil water availability, the maximum transpiration is determined by lai and $\mathrm{Rs}_{\min }$. The other parameters appearing in the stomatal resistance (or conductance) function, which in principle are species dependent, do not seem to affect very much the heat fluxes. The other land-surface parameters are relatively important only in some of the models, or under particular atmospheric conditions, e.g., vegetation albedo for sensible heat flux during day time, soil texture for BATS, emissivity for sensible heat flux during night time only in the ISBA scheme, etc.
Results obtained here are consistent with previous studies (i.e., Collins and Avissar, 1994; Henderson-Sellers, 1993), which attribute to soil moisture, surface roughness, albedo and, when vegetation covers the ground, leaf area index and stomatal resistance, a key role in the land-surface fluxes. When stomatal resistance is expressed as a function of soil wetness and environmental variables, then soil wetness becomes even more predominant.

The major production terms of turbulent kinetic energy (TKE) near the ground surface are shear and buoyancy (Garratt, 1992). Mechanical production by shear depends on the surface momentum flux and the vertical gradient of horizontal wind speed. Production by buoyancy depends on the vertical thermal stratification, and on the sensible heat flux. If shear production is dominant, as is the case under stable conditions, roughness length is the most important parameter for the land-surface scheme. If, on the other hand, buoyant production is dominant, as is the case 
during convective conditions, soil wetness and vegetation parameters are the most important parameters. Thus, depending on the stability of the atmospheric surface layer, different parameters become more or less important.

The FAST technique is a very powerful tool for intercomparison of land-surface algorithms. When assessing scheme performance, as, e.g., in the project for intercomparison of land-surface parameterization schemes (PILPS) (Henderson-Sellers et al., 1993, 1995), usually the different models have some degree of freedom in selecting the calibration parameters. Direct comparison of results (either for 1D or 3D simulations) involves bringing together algorithms, parameters, and calibration in field experiments. Consequently, difficulties often arise to evaluate properly the abilities of each particular scheme. The general application of objective sensitivity techniques, as FAST, facilitate this type of studies.

Further studies are needed to determine the sensitivity of surface schemes using FAST with real environmental conditions. This would include the use of field experiment datasets (FIFE, ARME, Cabauw, HAPEX-MOBILHY, etc.) for short and seasonal integrations. Real precipitation events followed by periods of drying would supply additional information about the sensitivity of landsurface schemes. Uncertainty in vegetation and soil parameters would be smaller, as their observation or estimate is well documented. The use of field experiment datasets would also prevent to select unrealistic combination of environmental conditions.

Once the most relevant parameters are clearly determined, subsequent progress could be oriented in reformulating schemes mainly based on such parameters. Other topics, such as compilation of physiografic data bases, aggregation procedures for parameters or assimilation techniques for some soil/surface variables, could be mainly focused on parameters which are of greatest importance in atmospheric modelling.

Finally, it should be stressed that the results presented here are quite general. Although the three considered schemes have a very different level of complexity, the same set of 3 or 4 parameters explains most of the heat fluxes variance. This is probably because these schemes are based on the same physical principles, namely the solution of energy and mass budget equations at the ground surface.

\section{Acknowledgments}

This study was performed while the first author was visiting the Department of Environmental Sciences at Rutgers University, supported by a Fulbright/Spanish Ministry of Development $(1996 \times 1997$ Program) grant. Comments and suggestions by B. Bringfelt and one anonymous reviewer significantly improved the manuscript.

\section{REFERENCES}

Avissar, R., Avissar, P., Mahrer, Y. and Bravdo, B. A. 1985. A model to simulate response of plant stomata to environmental conditions. Agric. For. Meteor. 34, 21-29.

Avissar, R. and Mahrer, Y. 1988. Mapping frost-sensitive areas with a three dimensional local scale numerical model. Part I: Physical and numerical aspects. J. Appl. Meteorol. 27, 400-413.

Avissar, R. and Pielke, R. A. 1989. A parameterization of heterogeneous land surfaces for atmospheric numerical models and its impact on regional meteorology. Mon. Wea. Rev. 117, 2113-2136.

Avissar, R. 1991. A statistical-dynamical approach to parameterize subgrid-scale land-surface heterogeneity in climate models. In: Land surface-atmosphere interactions for climate models: observations, models, and analyses. E. F. Wood, Ed. Kluwer, 155-178.

Avissar, R. 1992. Conceptual aspects of a statisticaldynamical approach to represent landscape subgrid- scale heterogeneities in atmospheric models. J. Geophys. Res. 97, 2729-2742.

Bougeault, P., Bret. B., Lacarrére, P. and Noilhan, J. 1991. An experiment with an advanced surface parameterization in a meso-beta-scale. Part II: The 16 June 1986 simulation. Mon. Wea. Rev. 119, 2374-2392.

Braud, I., Noilhan, J., Bessemoulin, P., Mascart, P., Haverkamp, R. and Vauclin, M. 1993. Bare-ground surface heat and water exchanges under dry conditions: observations and parameterization. BoundaryLayer Meteorol. 66, 173-200.

Bringfelt, B. 1996. Test of a new land-surface treatment in HIRLAM. HIRLAM technical report no. 23, Norrköping, Sweden (available from B. Bringfeldt, SMHI, S-60119 Norrköping, Sweden).

Carson, D. J. and Sangster, A. B. 1981. The influence of land-surface albedo and soil moisture on general circulation model simulations. GARP/WCRP: research activities in atmospheric and oceanic modeling, I. D. 
Rutherford, Eds. Numerical Experimentation Programme, Report no. 2, 5.14-5.21.

Charney, J. G., Quirk, W. J., Chow, S. H. and Kornfield, J. 1977. A comparative study of the effects of albedo on drought in semi-arid regions. J. Atmos. Sci. 34, 1366-1385.

Chervin, R. M. 1978. Response of the NCAR general circulation model to change land-surface albedo. Report of the JOC Study Conference on Climate models: performance, intercomparison and sensitivity studies, Washington, DC, GARP Publ. Series, no. 22, Vol. 1, 563-581.

Clapp, R. B. and Hornberger, G. M. 1978. Empirical equations for some soil hydraulic properties. Water Resour. Res. 14, 601-604.

Collins, D. and Avissar, R. 1994. An evaluation with the Fourier amplitude sensitivity test (FAST) of which land-surface parameters are of greatest importance for atmospheric modeling. J. Climate 7, 681-703.

Cukier, R. I., Fortuin, C. M., Shuler, K. E., Petschek, A. G. and Schaibly, J. H. 1973. Study of the sensitivity of coupled reaction systems to uncertainties in rate coefficients. I. Theory. J. Chem. Phys. 59, 3873-3878.

Cukier, R. I., Schaibly, J. H. and Shuler, K. E. 1975. Study of the sensitivity of coupled reaction systems to uncertainties in rate coefficients. I. Theory. J. Chem. Phys. 59, 873-3878.

Cukier R. I., Levine, H. B. and Shuler, K. E. 1978. Nonlinear sensitivity analysis of multiparameter model systems. J. Comp. Phys. 26, 1-42.

Dickinson, R. E. 1984. Modelling evapotranspiration for three-dimensional global climate models. Climate process and climate sensitivity. Geophysical Monograph 29, Maurice Ewing Volume 5, J. E. Hansen and T. Takahashi, Eds. American Geophysical Union, Washington, D.C., 58-72.

Dickinson, R. E. and Henderson-Sellers, A. 1988. Modelling tropical deforestation, a study of GCM landsurface parameterizations. Quart. J. R. Met. Soc. 114 439-462.

Dickinson, R. E. 1993. Biosphere-atmosphere transfer scheme (BATS) version 1e as coupled to the NCAR community climate model, NCAR Technical Note NCAR TN-387+STR. National Center for Atmospheric Research, Boulder, Colorado (available from R. E. Dickinson, Department of Atmospheric Physics, University of Arizona, Tucson, AZ).

Famiglietti, J. S. and Wood, E. F. 1991. Evapotranspiration and runoff from large land areas: land surface hydrology for atmospheric general circulation models. Surv. Geophys. 12, 179-204.

FAO/UNESCO. 1974. Soil map of the world. Food and Agriculture Organization (FAO), Paris, France.

Garratt, J. R. 1992. The atmospheric boundary layer. Cambridge Atmospheric and Space Science Series. Cambridge University Press, Cambridge, U.K., $316 \mathrm{pp}$.

Giard, D. and Bazile, E. 1997. Soil moisture assimilation in a global variable resolution NWP model. Proc. 13th
Conference on Hydrology, 2-7 February 1997, LongBeach, California, AMS

Giordani, H. 1993. Experiences de validation unidimensionelles du schema de surface NP89 aux normes ARPEGE sur 3 sites de la campagne EFEDA 91. Centre National de Recherche Meteorologique, Note de Centre no. 24, $20 \mathrm{pp}$. + Figures (avaialable from Meteo-France, Toulouse, France).

Henderson-Sellers, A. 1993. A factorial assessment of the sensitivity of the BATS land-surface parameterization scheme. J. Climate 6, 227-247.

Henderson-Sellers, A., Yang, Z. L. and Dickinson, R. E. 1993. The project for intercomparison of land-surface parameterization schemes. Bull. Amer. Met. Soc. 74, $1335-1349$.

Henderson-Sellers, A., Pitman, A. J., Love, P. K., Irannejad, P. and Chen, T. H. 1995. The project for intercomparison of land-surface parameterization schemes (PILPS): Phases 2 and 3. Bull. Amer. Met. Soc. 76, 489-503.

Henderson-Sellers, A. 1996a. Soil moisture: a critical focus for global change studies. Global and Planetary Change 13, 3-9.

Henderson-Sellers, A. 1996b. Soil moisture simulation: achievements of the RICE and PILPS intercomparison workshop and future directions. Global and Planetary Change 13, 99-115.

Henderson-Sellers, A. 1996c. Soil moisture: the landsurface "connexion". In GOALS, in GOALSymposium, pp. 107-110, American Meteorological Society.

Koster, R. D. and Suarez, M. J. 1992. A comparative analysis of two land surface heterogeneity representations. J. Climate 5, 1379-1390.

Jacquemin, B. and Noilhan, J. 1989. A study of rainfall interception using a land surface parameterization for mesoscale meteorological models. J. Appl. Meteor. 28, 1282-1302.

Jarvis, P. G. 1976. The interpretation of the variations in leaf water potential and stomatal conductance found in canopies in the field. Philos. Trans. Roy. Soc. London, Ser. B 273, 593-610.

Li, B. and Avissar, R. 1994. The impact of spatial variability of land-surface characteristics on land-surface heat fluxes. J. Climate 7, 527-537.

Liu, Y. and Avissar, R. 1996. Sensitivity of shallow convective precipitation induced by land-surface heteorogeneities to dynamical and cloud microphysical parameters. J. Geophys. Res. 101, 7477-7497.

Mahfouf, J. F. and Jacquemin, B. 1989. A study of rainfall interception using a land surface parameterization for mesoscale meteorological models. J. of Appl. Meteor. 28, 1282-1302

Mahfouf, J. F., Manzi, A. O., Noilhan, J., Giordani, H., Deque, M. 1995. The land surface squeme ISBA within the Meteo-France climate model ARPEGE. Part I: Implementation and preliminary results. J. Climate $\mathbf{8}$, 2039-2057.

Manzi, A. O. and Planton, S. 1994. Implementation of the ISBA parameterization scheme for land surface in

Tellus 50A (1998), 3 
a GCM - an annual cycle experiment. J. Hydrol. 155, 353-387.

McCumber, M. C. and Pielke, R. A. 1981. Simulation of the effects of surface fluxes of heat and moisture in a mesoscale numerical model: I Soil layer. J. Geophys. Res. 86, 9929-9938.

McKay, M. D., Beckman, R. J. and Conover, W. J. 1979. A comparison of three methods for selecting values of input variables in the analysis of output from a computer code. Technometrics 21, 239-245.

McRae, G. J., Tilden, J. W. and Seinfeld, J. H. 1982. Global sensitivity analysis - a computational implementation of the Fourier amplitude sensitivity test (FAST), Computer Chem. Eng. 6, 15-25.

Mintz, Y. 1984. The sensitivity of numerically simulated climates to land-surfaces conditions. In: The global climate, J. Houghton, Ed. Cambridge University Press, 79-105.

Miyakoda, K. and Strikler, R. F. 1981: Cumulative results of extended forecast experiments. Part III: Precipitation. Mon. Wea. Rev. 109, 830-842.

Noilhan, J. and Planton, S. 1989. A simple parameterization of land surface processes for meteorological models. Mon. Wea. Rev. 117, 536-549.

Noilhan, J. and Lacarrere, P. 1995. GCM gridscale evaporation from mesoscale modelling. J. Climate 8 , 206-223.

Noilhan, J., Mahfouf, J. F., Manzi, A. and Planton, S. 1993. Validations of land-surface parameterizations Developments and experience and the French weather service. Proc. Seminar ECMWF, 7-11 September 1992, ECMWF Reading, UK, 125-158.

Pielke, R. A. 1984. Mesoscale meteorological modeling. Academic Press, New York, 612 pp.

Rowntree, P. R. and Bolton, J. A. 1978. Experiments with soil moisture anomalies over Europe. The GARP programme on numerical experimentation: research activ- ities in atmospheric and oceanic modeling. R. Asselin, Ed. Report no. 18, WMO/ICSU, 63 pp.

Shukla, J. and Mintz, Y. 1982. Influence of land-surface evapotranspiration on the earth's climate. Science $\mathbf{2 1 5}$, 1498-1501.

Sud, Y. C., Shukla, J. and Mintz, Y. 1988. Influence of land-surface roughness on atmospheric circulation and precipitation: A sensitivity study with a general circulation model. J. Appl. Meteor. 27, 1036-1054.

Sud, Y. C., Sellers, P. J., Mintz, Y., Chou, M. D., Walker, G. K. and Smith, W. E. 1990. Influence of the biosphere on the global circulation and hydrological cycle - A GCM simulation experiment. Agric. For. Meteor. 52, 1036-1054.

Thompson, N., Barrie and Ayles, M. 1981. The Meteorological Office rainfall and evaporation calculation system: MORECS. Hydrological Memorandum $\mathbf{4 5}$ $69 \mathrm{pp}$

Uliasz, M. 1988. Application of the FAST method to analyze the sensitivity - uncertainty of a Lagrangian model of sulphur transport in Europe. Water, Air and Soil Pollution 40, 33-49.

U.S. Department of Agriculture. 1951. Soil survey manual. US Dep. Agr. Handbook 18, 1-503.

Walter, J. and Rowntree, P. R. 1977. The effect of soil moisture on circulation and rainfall in a tropical model. Quart. J. Roy. Meteor. Soc. 103, 29-46.

Wilson, M. F. 1984. The construction and use of land surface information in a general circulation climate model. Unpublished $\mathrm{PhD}$ thesis, University of Liverpool, United Kigdom, 346 pp.

Wilson, M. F. and Henderson-Sellers, A. 1985. A global archive of land cover and soils data sets use in general circulation models. J. Climate 5, 119-143.

Wilson, M. F., Henderson-Sellers, A., Dickinson, R. E. and Kennedy, P. J. 1987. Investigation of the sensitivity of the land-surface parameterization of the NCAR community climate model in regions of tundra vegetation. J. Climate 7, 319-343. 